This was the conclusion at which the second Royal Commission on Tuberculosis arrived. We have already seen that whatever danger attaches to milk comes mainly from cows with tuberculosis of the udder, and the public health would be almost entirely safeguarded from this danger if we could exclude such animals from our dairies. Periodical examination by competent inspectors would go a long way towards securing this object, but the inspection would require to be at rather short intervals, for tuberculosis of the udder may come into existence and attain most dangerous dimensions in a period of a few weeks. The more frequent the inspection the better, but of course this means a great deal of expense. If every town and rural district produced its own milk it would be a comparatively simple problem to organise and carry out a fairly efficient system of inspection of milch cows, but as the law at present stands the majority of the population cannot obtain this safeguard. With the exception of Glasgow, Manchester, and a few other places, a local authority has no power to inspect cows outside its own district, and the helpless position in which this state of the law leaves the inhabitants of London and other large towns is obvious. If cows of which the milk is sold for human food had everywhere to be submitted to periodical inspection such inspection would naturally be undertaken by the various local authorities, each of which would supervise the cows .and cowsheds in its own district; but the compulsory inspection of ail the milch cows in the country would .be a very large undertaking, and perhaps it would be premature to press for it. In the meantime :a good case can be made ont for making general the special powers relating to inspection of cows in outside districts which a few fortunate cities have acquired by special Acts of Parliament. This also was one of the directions in which the members of the second Royal Commission on Tuberculosis considered immediate action to be necessary.

There remain for consideration some other safeguards which would doubtless be less effective than those just discussed, but which, unlike these, would not be difficult to tenforce-viz. : (1) comptulsory notification of udder disease and of any symptoms of tuberculosis in milch cows, with, of course, the power to inflict a considerable fine for not reporting; and (2) the interdiction of the sale of milk from any cow suffering from tuberculous disease of the udder or exhibiting clinical signs of tuberculosis. Against the demand for the amendment of the existing law to the extent of granting the public these very reasonable safeguards against infection through milk it cannot be urged that they would be very expensive or that they would press harshly on private interests. The present state of the law, or rather the almost entire absence of any law, dealing with tuberculous disease of the udder in eows is a scandal and a reproach to -civilisation. It scarcely sounds credible, but it is a fact, that the owner of a cow in the most advanced state of tuberculosis, and exhibiting the most manifest signs of udder disease, may sell that cow's milk for human food as long as the sale has not been specially interdicted on the certificate of a veterinary surgeon, and that no penalty attaches to this crime of deliberately or carelessly placing on the market a food material charged with the germs of a dangerous disease In the interests of public health the sale of milk from tuberculous udders and from cows that are obviously tuberculous in any part of the body must be stopped, and it must be deolared illegal to ksep such animals alive. There need be no hesitation in pressing for this reform because the measures demanded are in the interests of the owners of cattle and would be advisable even if it were established that bovine tuberculosis is not transmissible to man. There is no dispute as to the danger of visibly tuberculous animals to others of their own species, and it is the very reverse of a hardship to the owner of such animals to insist on their being slaughtered.

It would probably be regarded as a serious omission if I did not refer to one other method of counteracting whatever danger at present attaches to impure milk as a cause of tuberculosis. No matter how highly charged milk may be with tubercle bacilli, it can be deprived of all danger from that source by raising it to the temperature known to be fatal to these germs. Less than the boiling temperature $\left(212^{\circ} \mathrm{F}\right.$.) suffices for this purpose ; but, unfortunately, the lowest temperature that can be relied upon imparts to the milk a flavour that many people find distasteful. That objection does not hold good in the case of infants and young children, and the custom of boiling or steaming the nursery milk for a few minutes cannot be made too general. But while abstinence from uncooked milk is a sure way of avoiding infection with bacilli present in that article of food, it cannot for a moment be admitted that this absolves public health authorities from all concern with the subject. Arsenical beer may be made harmless by adding the proper antidote before drinking it, but the most courageous brewer would not plead this as an excuse for selling the impure article.

In conclusion, I would venture to express the earnest hope that the Congress will not endorse the view that it is inadvisable to take any measures to prevent the transmission of tuberculosis from the lower animals to human beings. To justify the introduction of measures to that end it is not necessary to contend that this is a common method of infection, or that the danger arising from milk can for a moment be compared with that present in human sputum. The inhalation of tubercle bacilli expelled from the bodies of human patients is doubtless the great cause of human tuberculosis, and every practicable means of preventing infection in that way ought to be employed; but at the same time we ought not to concede to the milkmen the right to sell us tubercle bacilli, even if we were assured that -like Professor Koch's experimental pigs-we had nothing to fear beyond the development of "little nodules here and there in the lymphatic glands" of our necks and "a few grey tubercles" in our lungs.

\section{WHAT ADMINISTRATIVE MEASURES ARE NECESSARY FOR PREVENTING THE SALE TO THE PUBLIC OF TUBERCULOUS MEAT? ${ }^{1}$}

BY SHIRLEY F. MURPHY, M.R.C.S. ENG., L.S.A., MEDICAL OFFICER OF HEALTH TO THE ADMINISTRATIVE COUNTY OF LONDON.

WHEN I was asked to open a discussion at this Congress on the administrative measures which are necessary for preventing the sale to the public of tuberculous meat it was at once obvious to me that no new material, no new fact, could be submitted to the meeting. The measures which are necessary are well understood by those who have directed their attention to the subject and what is wanted now is not the knowledge by such persons of what to do but the education of the public in the necessity for adopting in this country measures which have been tried and found successful elsewhere. In England we are always slow to modify our procedure and in any matter which is held to affect a trade interest especially slow, for this interest at once provides an opposing force which renders the education of the public difficult. This force is able to manifest its power from the beginning and at a time when the public concern themselves little with the subject. It is only at a later stage that the public find that they have an interest at stake and that they must bestir themselves to put law makers and law administrators in motion. When once this position is arrived at we may look forward to success. Our Congress may do much by discussion of this subject to create a wider interest in it and by influencing public opinion to bring about the result which is hoped for by those who see the need for better supervision over meat-supplies.

It is not within our province in this section to consider whether or not the consumption of the meat of tuberculous animals is prejudicial to man. The title of the subject which $\mathrm{I}$ am invited to discuss implies that tuberculous meat must be excluded from the food-supply. This question has been considered by two Royal Commissions, the second of which was presided over by our chairman, Sir Herbert Maxwell. I shall later have to mention the conclusion at which this Commission arrived, and this because it has a necessary bearing upon the sort of administration which is needed, but I shall accept its conclusions and shall not enter into a discussion of pathological questions. I may, however, in commencement, briefly refer to the frequency with which tuberculous diseases affect cattle and the proportion of those which are slaughtered which must be deemed to be unfit for human food. If animals were rarely affected with this

1 A paper communicated to the British Congress on Tuberculosis Section I., State and Municipal. 
disease, it might be difficulti on this ground to claim the institution of an administration to prevent the sale of their meat to the public. This, however, is not the case, and it will suffice in evidence of this contention to quote the figures published by the first Royal Commission. This report shows that during a period of four years in the Copenhagen slaughter-house 17.7 per cent. of oxen and cows and 15.3 per cent. of swine were found to be tuberculous, and that in the Berlin slaughter-house in one year 15.1 per cent. of oxen and cows and $\mathbf{1 5 . 5}$ per cent. of swine were found to be tuberculous. Of the oxen and cows in the Berlin slaughter-house 1.26 per cent. were condemned on account of tuberculosis and 0.23 per cent. of swine. The report further says that the Commission has reason for thinking that in this country "the facts about tuberculous animals would exhibit a broad resemblance to the foregoing if such records could be obtained." The figures obtained from public slaughterhouses in Fingland are in no way conclusive of the amount of animals intended for food which are tuberculous or which are found to be unfit for human consumption. At the present time there is no need for the owner of an animal presenting signs of disease to have it slaughtered under conditions which would ensure its inspection. He can easily kill it elsewhere. I may state that among 18,440 cattle slaughtered in the Manchester public slaughter-house in $1896,48 \frac{1}{2}$ carcasses of cows and three carcasses of bullocks were condemned on account of tuberculosis, or about 0.3 per cent., being but about one-quarter of the proportion condemned in the Berlin slaughter-house. Mr. James King, the veterinary inspector of Manchester, who supplied the figures relating to that city, stated to the second Commission that very few cows are sent to the public slaughter-house from the country round. "People," he said, "are a little frightened to send cows to the abattoirs. They do not care to send them in where there is rigorous inspection. The cows go [he thought] to the districts outside, because the Manchester market received greater number of cows dressed than live cows coming to the abattoirs. The carcasses are brought in if it is thought they will pass in the Manchester market, and no doubt if they are badly diseased they are retained outside. That [he said] is my opinion about the matter." Mr. King is an officer of much experience, and his statements suffice to show that we must not assume that only one bovine animal in every three or four hundred is unfit for human consumption, for those entering the Manchester slaughter-house must be regarded as exclusive of a number which the owners believe to be too diseased to submit to inspection. It would be interesting to know what happens to those which are "retained outside," but for the moment I am concerned only to show that the proportion of cattle in this country which are tuberculous and which are unfit for human consumption is so large that if the public desire to avoid the consumption of their flesh they must provide an administrative system for the purpose. I may add the figures of another city to the above, taken also from the report of the second Commission. Dr. E. W. Hope, medical ofticer of health of Liverpool, stated that of 16,340 cattle slanghtered in the public slaughter-houses the carcasses of 214 were destroyed on account of tuberculosis-i.e., about 1.4 per cent., or about the same proportion as in Berlin. In the two cities which I have referred to it has not been the practice to condemn the Hesh of all animals which have suffered from tuberculous disease. In Manchester Mr. King stated that "if the disease is generalised the whole carcass is condemned; if it is only localised the localised part is removed and the remainder is passed." In Liverpool Dr. Hope said that if the disease were confined to the lung and the carcass generally was deteriorated then the carcass is seized, and it is also seized if the disease is very extensive and the carcass is not deteriorated.

I may now turn to the consideration of the amount of tuberculous disease which must be deemed to render the flesh of animals unfit for human consumption. Turning first to Germany, we find the practice is as follows. In Prussia the law of 1892 provides that (1) the flesh of tuberculous cattle is deemed unfit for food if it contains tubercle or if the tuberculous animal is emaciated, although there may be no tubercle in the flesh; and (2) that the flesh of tuberculous cattle may be considered fit for food if the animal is well nourished and $(a)$ the tubercle is found solely in one organ, or (b) in the event of two or more organs being diseased these organs lie in the same cavity of the body and are directly connected with each other either through the lymphvessels or through blood-vessels, which do not belong to the general circulation, but to the lungs and portal circulation. In Bavaria the law of 1892 provides that the flesh of cattle and swine shall be deemed fit for food if the tuberculosis is localised and in the first stage of development and the animal is in a well-nourished condition. 'The flesh is to be considered unfit for food if the animal is suffering from generalised and advanced tuberculosis and at the same time shows signs of emaciation. In Saxony the law of 1892 provides that the flesh of a tuberculous animal is to be deemed unfit for food (1) if the tuberculosis bas so far developed as to lead to emaciation and if the 1 esh differs in appearance from that of healthy flesh; (2) also if the same is generalised-i.e., if the spread of the tuberculous processes in the body can have taken place only by the circulation of the blood (excepting the portal circulation) and at the same time emaciation exists in a high degree. or the meat, or the bones, or the lymph glands belonging thereto are impregnated with tubercle; and (3) also if the disease is in the form of a generalised miliary tuberculosis with fever. In France the law of 1888 prohibits the sale of the flesh of tuberculous animals-(1) if the lesions are generalised-i.e., not confined exclusively in the visceral organs and their lymphatic glands; and (2) if the lesions, although localised, have invaded the major portion of a viscus or show themselves by occurring on the walls of the thoracic or abdominal cavities.

The second Royal Commission recommended that the entire carcass and all the organs should be seized if (1) there is miliary tuberculosis of both lungs; (2) when tuberculous lesions are present in the pleura and peritoneum; (3) when tuberculous lesions are present in the muscular system or in the lymphatic glands, embedded in or between the muscles; and (4) when tuberculous lesions exist in any part of an emaciated carcass, and that the carcass, if otherwise healthy, shall not be condemned, but every part of it containing tuberculous lesions shall be seized $(a)$ when the lesions are confined to the lungs and the thoracic lymphatic glands, (b) when the lesions are confined to the liver, (c) when the lesions are confined to the pharyngeal lymphatic glands, and $(d)$ when the lesions are confined to any combination of the foregoing but are collectively small in extent. In the case of the flesh of the pig it is recommended that, in view of the greater tendency to generalisation of tuberculosis in that animal, the presence of tuberculous deposit in any degree shall involve seizure of the whole carcass and of the organs.

If we may assume that it is necessary in the interest of the public health to enforce the requirements of these laws and recommendations-and I see no reason for any other view-we are obliged to consider the course which should be adopted for that purpose. The law in England as to meat inspection differs at the present time materially from that of other countries. In England the responsibility of determining whether the flesh of animals is fit or unfit for human food is cast upon the butcher. He is presnmed to have sufficient knowledge for that purpose, and the duty which is cast upon the sanitary authority is to see that he exercises his judgment properly. If he is found offering for sale meat which is unfit for food he cannot claim ignorance as his excuse; his meat is seized and he is subjected to penalty. The alternative method, which is that adopted in other countries where there is systematic meat inspection, easts the duty of determining whether the meat is fit for haman food on the local authority. The butcher brings to them the live animal which he is going to slaughter or the flesh of the slaughtered animal and they determine whether or not it shall be sold for food. While in England, therefore, meat is only occasionally inspected before sale in the countries referred to it is always inspected before sale. Which of these two methods is fairer to the public and to the butcher? Obvionsly it is impracticable to require all butchers to possess the knowledge which is implied in the regulations as to the meat of tuberculous animals which I have stated above, and, further, it is practically impossible to ensure that each of them will observe these regulations unless complete machinery is provided for this purpose. What then, have other countries done in this matter?

For what follows I am largely indebted to Professor Ostertag's excellent work on meat inspection. In Belgium the law of 1890 requires that all animals, inclnding pigs, whose flesh, intestines, fat or blood is intended for human food, must be examined, after slaughtering, by an expert who is either appointed by the town or, if this does not occur, by the Government for the commune in which the slaughtering 
takes place, and the communes may require inspection of the animal before slaughter. The conditions under which this is to take place are prescribed by the commune which also bears the cost. The inspection is generally made by veterinary surgeons Inspection of the carcass and viscera must take place at the latest within 12 hours of the slaughtering in summer and 24 hours in winter, and the carcass must not be cut up before inspection. The abdominal viscera must be taken out before the arrival of the expert and so preserved that their connexion with the particular carcass can be recognised; in the case of solipeds, the thoracic viscera, the bronchial tubes, and the larynx must remain in their natural position. If after the examination the meat, viscera, \&c., are found to be healthy the expert must stamp them with an approved stamp, in large animals on at least every quarter and in small animals on at least every half. If on examination the whole or part of the animal is considered to be unfit for food notice has to be given to the burgomaster who gives orders as to what shall be done with the carcass. If the owner of the animal is dissatisfied an appeal is provided. It is unlawful to sell meat which has been slaughtered contrarily to these regulations, and in the case of meat brought in from outside it is required that it shall only be the whole, or the half, or the quarter of the carcass, and the lungs must remain in their natural position; all must be examined and stamped. In Southern Germany, in part of Western and part of Central Germany, and in the free cities of Bremen, Lübeck, and Hamburg there is regulated meat inspection. Animals intended for human food must be examined before and after slaughter, in some places exemption being made for very young animals. In Northern Germany the conditions are not the same, nbligatory meat inspection being required in some parts, including Berlin, and not in others, examination for trichinosis alone being practically general. In Brunswick and Saxony, since 1898 , however, meat inspection is obligatory throughout, the law being very similar to that of Belgium.

In Sweden and Norway there have been laws requiring the provision of communal slaughter-houses since 1892 and since 1895 requiring meat inspection in the towns. Public slaughter-houses have, however, not been provided. In Norway there is at the present time, Dr. Bentzen informs me, only one public slaughter-house-viz., at Christiansundand in Sweden, I learn from Dr. Linroth, there is no public slaughter-house, but they are now proposed in Stockholm and Gottenburg and a few smaller towns. In Denmark Professor Ostertag states that in 1899 there were public slaughterhouses and meat inspection in seren towns. In AustroHungary he says that the law requires the inspection of slaughtered animals, but the method of administration had prevented uniformity of action. In Italy he writes that a good scheme for meat inspection became law in 1890 , but the regulation of meat being left to the provincial authorities has made a thorough reform impossible. The law requires the inspection of all animals intended for the food of man, the erection of public slaughter-houses in towns of more than 6000 inhabitants, and the stamping of meat, including the inspection of imported meat.

It is thus seen that already there is obligatory inspection of meat in some countries and that other countries are adopting the same course. I am not exaggerating the position if I say that the trend of opinion and of law in civilised Europe is to require that meat intended for human food shall be inspected by competent persons before it is sold for this purpose. All countries are not equally advanced in this matter, delay being often caused by the want of provision of the one condition which is essential to the carrying out of this intention-the provision of public slaughter-houses. I need not point out the absolute necessity of this provision, if effect is to be given to the recommendations of the Royal Commission on Tuberculosis, or the requirements of laws which have been adopted in other countries. So long as animals may be slaughtered in numerous private premises in our cities inspection cannot be carried out. The inspector must be present at the time of slaughter so as to ensure that regulations as to what is to be deemed fit for food and what is to be deemed unfit for food shall be complied with and to prevent the dishonest butcher from practising those arts which give to meat a fictitious appearance and which are well known to those who have experience of meat inspection. This is becoming generally recognised, and in Prussia, Professor Ostertag tells us, public slaughter-houses have in the last 20 years "literally grown out of the earth," so much so that in 1897 there were 321 public slanghter-houses in that kingdom and 40 were provided in the period 1895-97. This provision is, of course, required for other reasons than those which relate only to the prevention of tuberculous disease in man, but we may here claim that it is absolutely necessary on the score of the disease which this Congress is especially considering. It is the want of public slaughter-houses which stands in the way of effect being given in some of the continental countries to their law of obligatory meat inspection; it is the opposition to public slanghter-houses on the part of the butchers which is the chief obstacle to the institution of a system of meat inspection in this country.

I may therefore briefly refer to the objections which have been urged by the butchers' trade to the replacement of private by public slaughter-houses. One of these objections is that the price of meat would be increased. The effect in Germany of the system of slaughter in public slaughterhouses and of meat inspection has been carefully considered by Osthoff who came to the conclusion in 1894 that the cost of the administration represented a sum less than about onehalf of a farthing in the pound of meat. This is obviously a price of no practical importance when considered as a setoff against the advantage of the exclusion from sale for human food of meat which is unfit for the purpose. Dr. Schwartz, director of the town slaughter-house and cattle-market at Stolp, however, writing later, says: "The fear whether such establishments [public slaughter-houses] would pay or possibly cause an increase in the price of meat has been found to be quite groundless and has long. been disproved. That this latter cannot be the case is conclusively proved by the experience of many years which individual communes possess; on the contrary, one may rather maintain that the prices have gone down, since the quality of the meat has improved, but the price has remained the same, apart from the general rise in the prices of food." It has also been urged that the meat killed in public slaughterhouses would be less well cared for than the meat killed in private slaughter-houses. Such argument would not be used by those alike familiar with the procedure in public slaughterhouses on the continent and of private slaughter-houses in this country. Compare for a moment the difference between the opportunity given for slaughter in a well-appointed slaughter-house fitted with every convenience and with cold chambers, to which the carcasses are removed, with the opportunity which exists in the small outbuildings and sheds in the rear of private houses in an English town. It has been urged that the offal which is consumed by the poor would be lost if the animal be slaughtered in a public slaughterhouse. This, again, the experience of the public slaughter. houses of the continent shows, has no foundation. It has been urged that the butcher who has a private slaughterhouse is able to employ his men at one time in slaughtering. and at another time in his shop or calling for orders. There is no reason why, if the butcher prefers it, they should not be equally employed in the public slaughter-house as in the private slaughter-house. It has been urged that if there were no private slaughter-houses there would be risk of a "ring" being formed to the detriment of the public. Obviously the best safeguard to the formation of a ring is to give to everyone selling meat the opportunity to slaughter his own animals. At the present time in London only a small proportion of meat vendors have this opportunity, and the rest depend, in the main, upon the middleman. They have no opportunity of slaughtering:

It has been said that the effect of the replacement of private by public slaughter-houses wonld tend to the exclusion from the meat market of English-grown cattle. Obviously so far as London is concerned the result would be the opposite, for every meat vendor would be able to purchase his own meat alive, instead of depending upon middlemen who may prefer to supply him with the meat of foreign animals. I am satisfied that the use of the public slaughter-house is directly in the interest of the butcher who would save in expense and who would be able especially to save by using the meat-cooling chambers associated with it, I recently made some inquiry as to the cost incurred in London by London butchers in providing ice for their icesafes in hot weather. The amount is enormous and for this the public have eventually to pay in the price of the meat they purchase.

It has been asserted that public slanghter-houses will be a charge upon the public purse. This, again, is not in accord with continental experience. At the time when the second Royal Commission on Tuberculosis was sitting several of its 
members, including its chairman, visited a number of public slaughter-houses on the continent and reported that "all the public slaughter-houses in Germany are self-supporting." A commission in Saxony, appointed in 1893, investigated the subject of the finances of public slaughter-houses. They reported thatAs soon as: the project [the establishment of public slaughter-
house] is mentioned-the butchers (the traders most interested therein) almost always oppose it, fearing various inconveniences to which their trade may be subjected in connexion with a public slaughter-house and its compulsory use, not the least of which is the stricter control of their business which comes with a public slaughter-house. Added to this, they raise the question of cost and they hold out the prospect of an increase in the price of meat-a fact which carries weight with the public and with the representatives of the community. But if public opinion is not influenced by this opposition and by these fears of the butchers, and if the leading citizens are of opinion that a slaughter-house is necessary, the butchers almost always abandon their opposition suddenly, recognise the necessity of a slaughter-house, and at the same time demand the right to build, arrange, and administer it themselves. Apart from other reasons not necessary to discuss here the finance question is placed in the front rank by the butchers. While they seek to attack the citizen on his weakest side, the not inconsiderable cost of building, the citizen on his weakest side, the not inconsiderable cost of building, arrangement, and administration of a public slaughter-house is unduly brought forward by the butchers, and the prospect is held out of a heavy charge on the finances of the town, increased taxation, dc. It is important to emphasise that the establishment of a public slaughter house is in no way prejudicial to the finances of a town or increase the taxes of the citizens, but that the funds devoted to the building and management are a very good investment. This the butchers guilds and other persons who offer to build slaughter-houses know very well, and with this reason strive with all their might that this favourable financial project shall not escape them. But in
matter the local authority has a predominant interest.

The Commission states that the receipts, without burdening the trader with heavy fees, provide, after payment of expenses, an interest of from 5 to 6 per cent. as well as a contribution to a sinking fund which will extinguish the debt in from 35 to 40 years.

I have dwelt upon this financial question at some length because only a few years ago London went through the first phase which the Saxon Commission describes. In England, therefore, we must, if we are to prevent the sale of tuberculous meat to the public, provide for and insist upon the slaughter of all animals intended for food in public slaughterhouses and we must provide competent meat inspectors for that purpose. The question has to be considered to whom shall this duty of meat inspection be entrusted. It is perfectly clear that the work must devolve upon those who have as a basis of the knowledge of meat inspection a knowledge of pathology, and this at once narruws the question down to the selection of members of one of the two professions having such knowledge-the medical and the veterinary. I do not think that in this country we shall ever relieve the medical officer of health of the duty of determining what is to be deemed fit for the food of man, nor is it desirable that this should be done; but in the actual carrying out of the work I believe we should do well to enlist much more than we have done in the past the services of members of the veterinary profession, and that we shall find that as they qualify themselves for this special duty they will be able to serve the purpose which we have in view.

In conclusion, then, I may say that the time has fully come when we should follow the excellent example which has been set us by other countries, that we should require all the animals which are killed in urban districts for human food to be slaughtered in public slaughter-houses, where there can be inspection before, at the time of, and after slaughter of the animal, that the meat shall be stamped, and that the public should be taught to look for this stamping as the test of wholesomeness rather than have to rely upon the pathological knowledge of the butcher and the housewife. Further, that all meat which has been killed outside a district, other than that which may have been killed in some public slaughter-house and which bears the evidence of inspection, shall be taken to meatinspection stations for examination. Greater difficulty no doubt attends the inspection of meat in village communities, but even in such sparse populations the veterinary surgeon is to be found, and it is quite possible to organise a system by which his services are available when animals are killed for food. We are not now concerned with any question of other disease than tuberculosis, but I may refer to the enormous gain which it would be to the community to exclude from the human food-supply the meat of diseased animals which now can, practically without let or hindrance, find its way to the consumer. It would prevent, what has been within my own knowledge, meat from knackers' premises being sent regularly to London from the provinces, and it would ensure to the poor people among us that in purchasing meat they were receiving the value of their money. It would, however, do much more than I have stated, and especially in. respect of tuberculosis, for in closing the door to the ready disposal of the meat of tuberculous animals it would compel the stock-owner to take steps to prevent the infection of his herd and would lead to the earlier exclusion from the milk-supply of animals manifesting symptoms of tuberculosis, for the interest of the cow-owner would be to slaughter them before disease became advanced.

I beg to move :-

That, in the opinion of this section, the meat of all animals intended for human food should be inspected before being sold for that purpose, and that in all urban districts, and in all rural districts as far as possible, such animals should be slaughtered in public slaughter-houses,
so as to ensure efficient inspection.

\section{THE VETERINARY WORK DONE UNDER THE MILK CLAUSES IN MANCHESTER AND THE DIFFICULTIES MET WITH.'}

By J. S. LLOYD, M.R.C.V.S.,

LATE VETERINARY SURGEON TO THE SANITARY COMMITTEE, CITY OF MANCHESTER.

BETwEEN the dates Jan. 11th, 1900, and April 30th, 1901, the number of farms from which samples of mixed milk have been taken at the Manchester railway stations or en route to the city has been 401 . Of these 259 are situate in Cheshire, and from 42 of these (or 16.21 per cent.) tuberculous milk has been sent to Manchester; 41 are situate in Staffordshire, from one of which (or 2.44 per cent.) tuberculous milk has been sent to Manchester; 93 are situate in Derbyshire, from four of which (or 43 per cent.) tuberculous milk has been sent to Manchester; whilst three are situate in Salop and five in Lancashire, all of which were free from tuberculous infection. From figures supplied by the farmers themselves to the public health office, the estimated number of cows kept at these 401' farms is 8408 or an average of nearly 21 cows per farm.

The total number of farms from which tuberculous samples have been sent is 47 (or 11.72 per cent). At 31 of these 47 farms 35 cows with tuberculous udders have been found. At 15 of these farms no cows having diseased udders could be found, and subsequent control samples of the mixed milk from these farms have all been reported free from infection after being tested by Professor S. Delépine. In one instance the result of inoculation is undeclared. At most of these farms the owners have admitted selling cows from the farms between the date of the taking of the mixed sample at the station and the date of the visit of the veterinary surgeon, but only in two or three instances have the owners admitted that the cows sold were diseased, and in only one case has a farmer admitted that the cow had a diseased udder. In three of these instances the farmers stated that they also sent the milk from a neighbour's cows together with the milk from their own cows, and in two cases these were followed up, but with negative results. At the remaining one of the 47 farms samples of the milk from suspicious cows are still in process of examination.

To give the percentage of cows having tuberculous udders among the cows represented on the 401 farms from which the mixed milk sent into Manchester was tested it will be necessary to strike out the 15 farms at which no cows with tuberculous udders could be found and also the one farm from which the milk from suspicious cows is still under investigation. The average number of cows will then be represented by $\frac{3}{4} \frac{1}{7}$ of $8408=5545$, which, taking 35 cows at the 31 farms, gives a percentage of 0.63 .

The total number of cows clinically examined as the result of following tuberculous samples of mixed milk is 1308, but the number of cows examined irrespectively of previous samples of mixed milk is 4031 . Of these 2182 were examined in the Manchester cowsheds, and among them eight cows were found to have tuberculous udders. This gives a percentage

1 A paper communicated to the British Congress on Tuberculosir Section I., State and Municipal. 